\title{
Beverages of coffee tree leaves
}

\begin{abstract}
Background: The objective of this research was to analyze the use of coffee leaves that are residues from the production of coffee, for the preparation of beverages. A comparison is made with the processing of mate, a drink spread in the south of Brazil. Leaves of mate and coffee have had the enzymes inactivated following a drying. The dried leaves were used for beverage preparation. A sensorial analysis was performed using the nine-point hedonic scale to evaluate the flavor of the beverages. For the taste of the drink, the scores greater than or equal to 6 were around $80 \%$ for the beverage obtained from the coffee leaves, $49 \%$ for the black tea and $84 \%$ for the yerba mate. The highest percentage of grades was 7 , consisting of $31.37 \%$ for coffee leaves, 19.61 for black tea and 27.45 for mate. The results make it possible to predict the possibility of using the leaves of coffee for a new beverage and to increase the income of coffee growers.
\end{abstract}

Keywords: leaves of coffee processing, new beverage, leaves drying, flavor beverage
Volume 7 Issue 4 - 2018

\author{
José Roberto Delalibera Finzer,' Alice \\ Teresa Valduga, ${ }^{2}$ Margarete Martins Pereira \\ Ferreira, ${ }^{3}$ Itamar Luis Goncalves ${ }^{4}$ \\ 'Chemical Engineering, Uberaba University, Brazil \\ ${ }^{2}$ Graduate Program in Ecology, Integrated Regional University, \\ Brazil \\ ${ }^{3}$ Institute of Chemistry, Goiás Federal University, Brazil \\ ${ }^{4}$ Faculty of Pharmacy, Federal University Rio Grande do Sul, \\ Brazil
}

Correspondence: José Roberto Delalibera Finzer, Chemical Engineering, Uberaba University, Campus Aeroporto, Av. Nenê Sabino I80I, Uberaba/MG. CEP 38.055-500, Brazil,Tel +55 34 3331.5854, Email jrdfinzer@pq.cnpq.br

Received: April 02, 2018| Published: July 03, 2018

\section{Introduction}

The Canadian company Wize Monkey makes use of coffee leaves in non-productive fruit periods for the production of coffee leaf tea. There are consumers of the coffee leaf beverage on three continents. Coffee and Caméllia sinensis, are the two species most consumed and investigated around the world have functional effects, due to their secondary metabolites. The majority phytochemical components are methylxanthines, and phenolic compounds. ${ }^{1,2}$ The last group is very heterogeneous in chemical diversity, involving phenolic acids, chlorogenic acids, and flavonoids, who have proved antioxidant effect. The main biological action of methylxanthines is related with modifications in vigil status, in order to improve cognitive abilities. ${ }^{3}$

The main physiological effect of caffeine "trimethylxanthine" is the stimulant of the central nervous system. Caffeine has an effect on the cardiovascular system causing an increase in blood pressure. These effects are observed when the individual ingests a dose of $250 \mathrm{mg}$ of caffeine (one cup of coffee has on average $70 \mathrm{mg}$ of caffeine). However, this effect disappears after repeated ingestion of the same dose "three times a day for seven days". ${ }^{4}$

The caffeine content found in the bark of the coffee fruits $(1.30 \%)$ is close to that found in the grain, $(1.12 \%),{ }^{5}$ and the leaves are of the same order of magnitude ( 0.8 to $1,9 \%$ ), dry weigth. ${ }^{6}$ The aim of this work was to study the extraction of soluble in coffee leaves in specific processing steps: inactivation and drying and to evaluate the acceptance, in relation to flavor, of the beverage obtained from the processed leaves.

\section{Methods}

Initially, the coffee leaves should have the enzymatic complex inactivated (Figure 1) to avoid darkening and formation of substances with undesirable flavor.

\section{Results}

Figure 2 shows aspects of the leaves of coffee: a) in natura; b) inactivated and c) dried with the procedure used in this research. The appearance of dried leaves is attractive which is indicative of the quality of the drink. For comparison, drinks with traditional leaves were prepared: black tea and yerba mate, results in Figure 3.

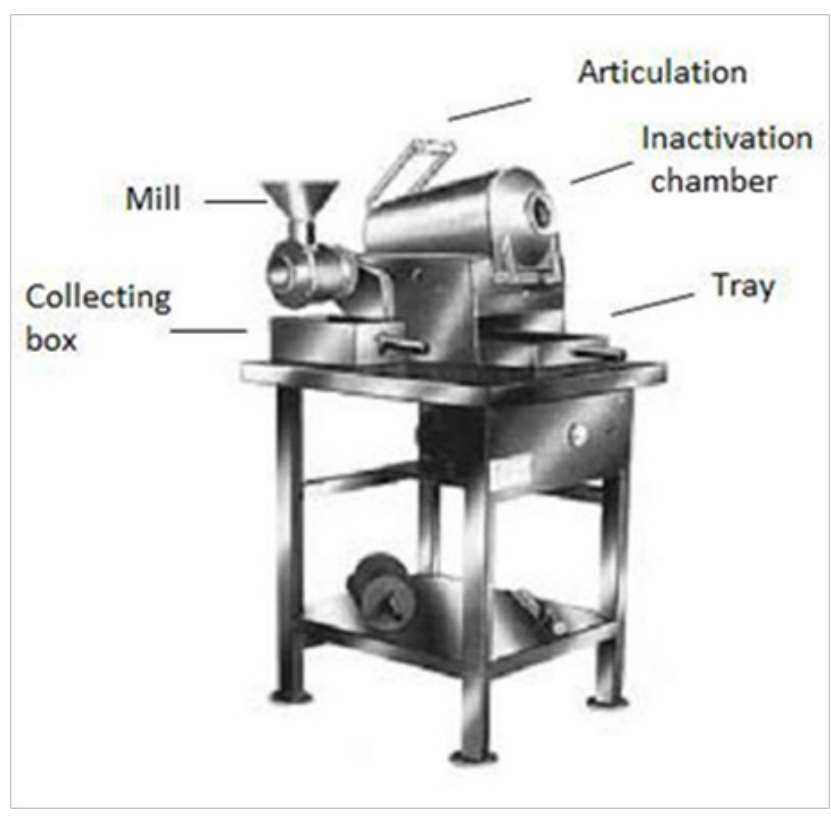

Figure I Scheme of an enzymatic inactivator with mill. ${ }^{5}$

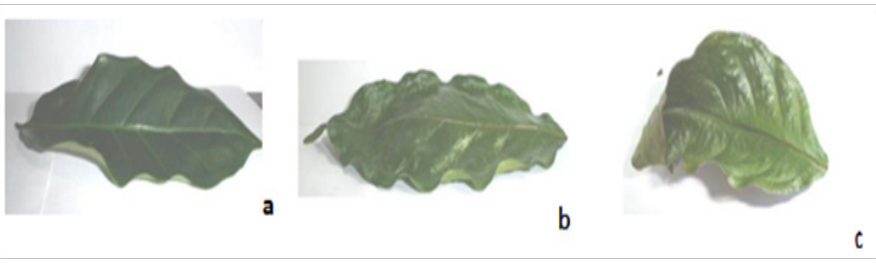

Figure 2 Images of coffee leaves: (a) "in natura", moisture 68\% (wb); (b) after inactivation and (c) after drying moisture $5 \%(w b)$. 


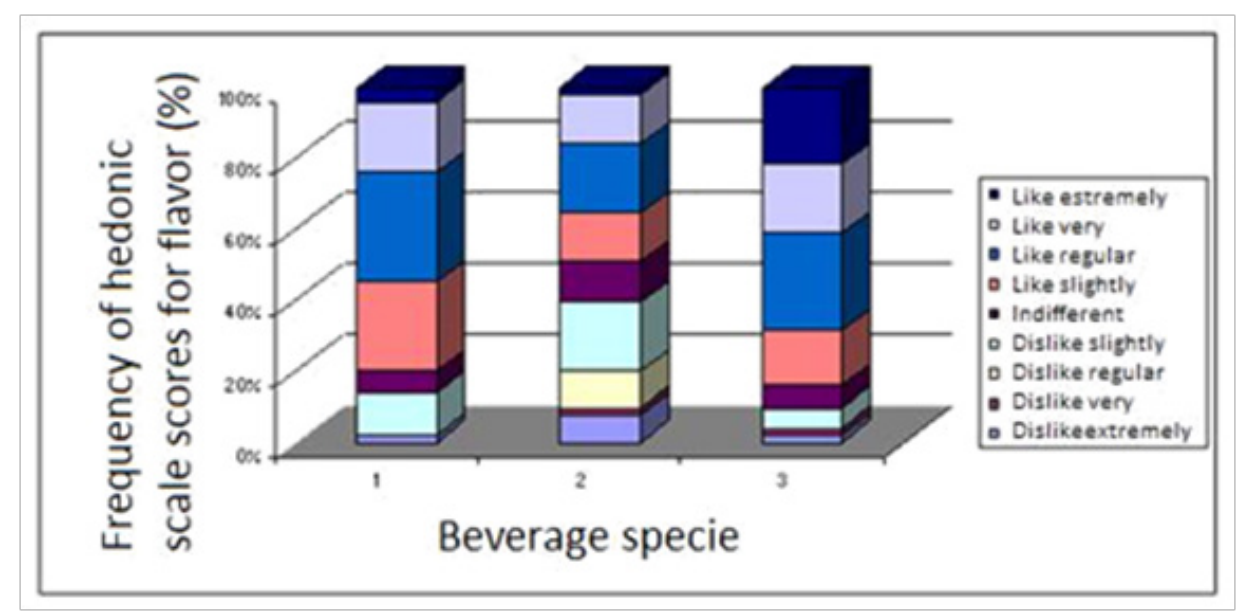

Figure 3 Histograms of notes percentages of hedonic scale for flavor, in sensory testing for drink prepared with: (I) coffee leaves processed, (2) black tea and (3) of yerba mate.

\section{Discussion}

The coffee leaf beverage was well appreciated by the tasters who carried out the sensory analysis, as shown in Figure 3. ANOVA for aroma analysis showed that at 0.05 significance levels, there was no difference between the tasters $(\mathrm{p}=0.31, \mathrm{p} \geq 0.05)$, that is, there was agreement among the tasters acceptance of the aroma for all three types of drinks.

\section{Conclusion}

For the taste of the drink, the scores greater than or equal to 6 were around $80 \%$ for the beverage obtained from the coffee leaves, $49 \%$ for the black tea and $84 \%$ for the toasted yerba mate. The highest percentage of grades was 7 , consisting of $31.37 \%$ for coffee leaves, 19.61 for black tea and 27.45 for mate. The results make it possible to predict the possibility of using the leaves of coffee for a new beverage and to increase the income of coffee growers. The leaves of mate with the initial humidity of $61.9 \%$ (wet basis), reduces to $14.6 \%(\mathrm{wb})$ after inactivation at temperature of $180^{\circ} \mathrm{C}$, and after drying to $4.3 \%(\mathrm{wb}){ }^{7,8}$ For coffee leaves processed with the same procedure, they had the final moisture of $5.0 \%(\mathrm{wb})$.

\section{Acknowledgements}

None.

\section{Conflict of interest}

Author declares that there is no conflict of interest.

\section{References}

1. Wang Y, CT Ho. Polyphenolic Chemistry of Tea and Coffee: A Century of Progress. J Agric Food Chem. 2009;57(18): 8109-8114.

2. Chacko SM, PT Thambi, R Kuttan, et al. Beneficial effects of green tea: A literature review. Chinese Medicine 2010;5:13-13.

3. Evans WC. Trease and Evans' Pharmacognosy. Nottingham: Elsevier Health Sciences. 2009.

4. Sfredo MA. Study of the Dispersion in the Drying of Coffee Fruits in Dryer of Vibrated Trays. Uberlândia Federal University: 2006; 319 p.

5. Yoshida LM. Soluble extraction of the roasted coffee husk. Uberlândia Federal University; 2005: 198 p.

6. Ashihara H, Kato M, Crozier A. Distribution, Biosynthesis and Catabolism of Methylxanthines in Plants. In: Hofmann FB, editor. Stockholm: Springer; 2011.

7. Valduga AT, Finzer JRD, Mosele SH. Processing of mate. Erechim: EDIFAPES; 2003: $182 \mathrm{p}$.

8. Finzer JRD, Valduga AT, Parckert ET, et al. Processing Leaves for the Preparation of Beverages. Food and Public Health. 2013;3(6):257-266. 